G531(P) A COHORT STUDY OF WHETHER PARENTAL SEPARATION AND LACK OF CONTACT WITH A PARENT PREDICTS DISEASE SEVERITY AT DIAGNOSIS IN YOUNG PEOPLES CHRONIC FATIGUE SYNDROME/MYALGIC ENCEPHALOMYELITIS

${ }^{1} \mathrm{~N}$ Ayadi O'Donnell, ${ }^{2} \mathrm{~A}$ McCourt, ${ }^{2} \mathrm{~T}$ Segal. ${ }^{1} \mathrm{C}$ ildren and young people's services, UCL Hospital FT, London, UK; ${ }^{2}$ Medical School, UCL, London, UK

\subsection{6/archdischild-2020-rcpch.449}

Aims Chronic Fatigue Syndrome (CFS)/myalgic encephalomyelitis (ME) is a complex condition of variable severity, affecting the physical and mental wellbeing young people. Triggers are recognised such as infection, physical illness or emotional distress. There has also been a link between adverse childhood events and likelihood of CFS/ME in later life. This cohort study looked at whether those with CFS have a higher incidence of parental separation, lack of contact with a parent and whether this sub-group have more severe disease at diagnosis.

Methods Retrospective analysis of the notes of 123 patients who attended a tertiary level adolescent CFS/ME service between April 2012 and April 2014 was conducted with further sub-group breakdown of those with parental separation and lack of contact with a parent with analysis on whether this group had an increase disease severity of CFS/ME at diagnosis.

Results Out of a total of 123 patients, 38\% (n=45) had parents who were separated, compared with $10.6 \%$ of families nationally defined as a one parent household. Furthermore, $66 \%(n=32)$ with separated parents had lack of contact with at least one parent. Most patients in this cohort had moderate CFS at diagnosis (defined by NICE as having reduced mobility and restriction in all activities of daily living). Further sub-group analysis of those with separated parents showed no difference in severity compared to the non-separated group $(p=0.69)$. There was no difference in disease severity for the group who lacked contact with at least one parent $(p=0.51)$.

Conclusion Parental separation or lack of contact is not related to severity of CFS at diagnosis in this cohort. Larger cohort analysis of the demographics of those with CFS/ME is needed to attempt prediction of those who are more at risk of having severe CFS/ME, the impact of family history of CFS/ME and the impact on school attendance and bullying on severity. Further analysis of family structure and whether this impacts on response to treatment is also needed as this may help influence the structure and support of treatment.

\section{G532(P) 'SCFN' (SUBCUTANEOUS FAT NECROSIS) OF THE NEWBORN - AN IMPORTANT DIFFERENTIAL DIAGNOSIS IN EVALUATION FOR CAUSES OF BRUISE-LIKE SKIN LESIONS IN A NEONATE}

UA Khan, E Clifford, M Moclair, R Barry. Department of Paediatrics, Mercy University Hospital, Cork, Ireland

\subsection{6/archdischild-2020-rcpch.450}

Introduction SCFN of the newborn is an uncommon, self-limiting panniculitis characterized by development of erythematous, firm, indurated plaques or nodules commonly over the extremities, back, buttocks and thighs, mostly occurring in term or post term babies within the first few weeks after birth. Hypercalcaemia is a life threatening complication which requires monitoring for several months.Perinatal mechanical stress, tissue hypoxia, and hypothermia may contribute to the pathogenesis. Exact incidence is unknown with a nearly equal male to female ratio.

Case Background We report a neonate presenting to emergency department by parents at 10 days of life from home with a sudden onset bruise-like linear lesion $6 \mathrm{~cm}$ long and $1.5 \mathrm{~cm}$ wide extending from the midline of upper part of the back to the right axilla. There was no history of trauma and baby was born via NVD. The skin lesion was red/purple in colour, non tender and palpable on examination. Clinical examination was otherwise unremarkable. As the marks on the back were suggestive of bruising, the baby underwent detailed Non Accidental Injury (NAI) investigations and social services assessment. Coagulation studies and FBC were normal. MRI brain reported subdural haematoma and suspected skull fracture, making NAI a strong consideration. Ophthalmology assessment and skeletal survey were normal. CT Skull was advised and this excluded skull fracture in favour of vermian skull bones. The origin of the subdural haematoma was then deemed uncertain but reported to be likely associated with vaginal delivery. Dermatology consultation confirmed the clinical diagnosis of SCFN of newborn.

Conclusion SCFN is a rare but important condition to consider in young infants who present with unexplained bruiselike lesions which require thorough investigation and consideration of possible NAI. Dermatology opinion was very helpful and should be sought if there is uncertainty about differential diagnosis.

\section{G533(P) TIME FOR A KITKAT? AN ANALYSIS OF NIGHT SHIFT BREAK HABITS IN JUNIOR DOCTORS}

${ }^{1}$ SD Ahsan, ${ }^{1} \mathrm{~N}$ Khanderia, ${ }^{1} \mathrm{~B}$ Mirza, ${ }^{2} \mathrm{~A}$ Roueche, ${ }^{2} \mathrm{M}$ Butler. ${ }^{1} \mathrm{G} K T$ School of Medical Education, King's College London, London, UK; ${ }^{2}$ General Paediatrics, Evelina London Children's Hospital, London, UK

\subsection{6/archdischild-2020-rcpch.451}

Background/Introduction In the climate of increased patient safety awareness, the BMJ launched the 2019 'give us a break' campaign urging doctors to take breaks to combat fatigue. A cross-sectional survey of junior doctors found poor break uptake with further studies showing that fatigue is associated with medical errors. ${ }^{1} 2$

$\operatorname{Aim}(\mathrm{s}) /$ Objectives

- Establish whether night-shift doctors are taking breaks.

- Improve the percentage of doctors taking night-shift

Methods Four PDSA cycles were developed including:

- Implementing break rota charts

- Raising awareness at the Junior Doctor Forum

- Implementing a Whatsapp group for the night team

- Raising awareness about the importance of breaks with posters

Results Baseline data showed break uptake in 100\% of Paediatric Nurse Practitioners (PNPs) whilst $0 \%$ of the general team doctors and $50 \%$ of specialty doctors were taking breaks. Post night-shift surveys identified common reasons. PDSA1 showed break uptake in $50 \%$ of doctors from both 